\title{
The Burden of Progressive Fibrosing Interstitial Lung Disease: A DELPHI Approach
}

\author{
Wim A. Wuyts · Spyridon Papiris · Effrosyni Manali · Maritta Kilpeläinen • \\ Jesper Rømhild Davidsen · Jelle Miedema • Carlos Robalo-Cordeiro • \\ Antonio Morais · Maite Artés (D) - Guus Asijee · David Cendoya • \\ Stéphane Soulard
}

Received: March 15, 2020 / Published online: May 22, 2020

(c) The Author(s) 2020

\section{ABSTRACT}

Introduction: The term progressive fibrosing interstitial lung disease (ILD) describes patients with fibrotic ILDs who, irrespective of the aetiology of the disease, show a progressive course of their disease despite current available (and non-licensed) treatment. Besides in idiopathic

Digital Features To view digital features for this article go to https://doi.org/10.6084/m9.figshare.12264599.

Electronic supplementary material The online version of this article (https://doi.org/10.1007/s12325020-01384-0) contains supplementary material, which is available to authorized users.

W. A. Wuyts

Unit for Interstitial Lung Diseases, Department of Respiratory Medicine, University Hospitals Leuven, Leuven, Belgium

\section{S. Papiris · E. Manali}

2nd Pulmonary Medicine Department, General

University Hospital "Attikon", Medical School,

National and Kapodistrian University of Athens,

Athens, Greece

\section{Kilpeläinen}

Division of Medicine, Department of Pulmonary

Diseases and Clinical Allergology, Turku University

Hospital and University of Turku, Turku, Finland

J. R. Davidsen

South Danish Center for Interstitial Lung Diseases,

Department of Respiratory Medicine, Odense

University Hospital, Odense, Denmark pulmonary fibrosis, little is known about management and the burden of patients with fibrotic ILD, particularly those with a progressive behaviour.

Methods: Using the Delphi method, 40 European experts in ILD management delivered information on management of (progressive) fibrosing ILD and on the impact of the disease on patients' quality of life (QoL) and healthcare resource utilisation (HCRU). Annual costs were calculated for progressive and non-/slow-progressive fibrosing ILD for diagnosis, follow-up management, exacerbation management, and end-of-life care based on the survey data.

Results: Physicians reported that progression in fibrosing ILD worsens QoL in both patients and

J. Miedema

Department of Respiratory Medicine, Erasmus

University Medical Centre, Rotterdam,

The Netherlands

C. Robalo-Cordeiro

Department of Pulmonology and Allergy, University Hospital of Coimbra, Coimbra, Portugal

A. Morais

Department of Pneumology of São João Hospital Centre, Diffuse Lung Diseases Unit, Oporto, Portugal

M. Artés ( $\square)$

Adelphi Spain, Barcelona, Spain

e-mail: maite.artes@adelphi.es

G. Asijee $\cdot$ D. Cendoya $\cdot$ S. Soulard Boehringer Ingelheim, Amsterdam, The Netherlands 
their caregivers. Progression of fibrosing ILD was associated with a greater use of HCRU for follow-up visits and maintenance treatment compared with the non-/slow progression. The number of patients who suffered at least one acute exacerbation was reported to be more than three times higher in progressive fibrosing ILD patients than in patients with non-/slowprogressive fibrosing ILD. On average, annual estimated costs of progressive fibrosing ILD per patient were 1.8 times higher than those of the non-/slow-progressive form of the disease.

Conclusions: Progression in fibrosing ILD causes a significant impact on QoL and HCRU and costs. These survey data underline the need for safe and effective therapies to slow the disease progression.

Keywords: Burden of disease; Consensus; Cost study; Delphi; European countries; Interstitial lung disease; Progressive fibrosing; Pulmonary; Societal impact

\section{Key Summary Points}

Why carry out this study?

A significant number of patients with fibrosing interstitial lung diseases (ILD) show a progressive behaviour that may lead to rapid health deterioration and early death, but little is known about the management and burden of these progressive fibrosing ILD patients.

Disease progression in fibrosing ILD affects patients' quality of life and increases healthcare resource use, and it is estimated to cost 1.8 times more than the non-progressive stage of fibrosing ILD.

\section{What was learned from this study?}

This Delphi study provides novel information on experts' management of fibrosing ILD and estimates the burden of disease of fibrosing ILD and the impact of its progression.

\section{INTRODUCTION}

Fibrosing interstitial lung diseases (ILDs) form a large and heterogeneous group of disorders that cause fibrosis in the lung parenchyma [1]. The most common form is idiopathic pulmonary fibrosis (IPF), which is characterised by progressive fibrosis, decline in lung function, progressive worsening of dyspnoea, and early mortality [2].

Despite differences in aetiology and clinical presentation, other ILDs may develop with progressive fibrosis and resemble IPF, with decline of lung function, worsening of respiratory symptoms, and non-responsiveness to treatment with anti-inflammatory or immunomodulatory agents $[1,3,4]$. It has recently been suggested that this progressive fibrosing behaviour shares some similar biological and clinical features and that patients with ILD who present this behaviour can be grouped as patients with progressive fibrosing ILD [3, 5]. The prevalence of progressive fibrosing ILD other than IPF (non-IPF progressive fibrosing ILD) is not known, but may be similar to the prevalence of IPF $[6,7]$. Recent studies have suggested a prevalence in the European population that ranges between $0.63-7.60 / 10,000$ for fibrosing ILD and between $0.5-6.72 / 10,000$ for non-IPF fibrosing ILD [7-10].

The socioeconomic burden of IPF is considerable. IPF has a significant impact on daily functioning and patients' quality of life $[11,12]$ and represents a substantial burden on the healthcare system [13]. Similarly, non-IPF progressive fibrosing ILD impairs patients' quality of life and, because of its resemblance in pathogenesis, is expected to increase the use of healthcare resources and costs in a comparable way $[12,14]$.

Overall, there is still little information on the definition, management, and socioeconomic burden of non-IPF progressive fibrosing ILD. The aims of this study were to evaluate the consensus among healthcare providers on the concept and management of non-IPF progressive fibrosing ILD and to estimate the burden of disease of progression in non-IPF fibrosing ILD in mid-sized European countries. 


\section{METHODS}

\section{Study Design, Participants, and Delphi Survey}

The Burden of Interstitial Consensus Panel (BUILDup) study used a modified Delphi method to evaluate consensus on the definition and management of progressive fibrosing ILD and to estimate the impact and economic burden of progression in non-IPF fibrosing ILD.

A brief description of the BUILDup study is as follows: the Steering Committee included eight members from six European countries: Belgium $(\mathrm{WW})$, Denmark (JRD), Finland (MK), Greece (SP and EM), The Netherlands (JM), and Portugal (AM and CRC). The Delphi questionnaire (Appendix 1) was designed based on a Boolean literature search in PubMed using "fibrosing" AND "interstitial lung disease" AND "progressive" as search terms and on the clinical expertise of the Steering Committee. A total of 138 panellists (about 15 per country) were contacted to participate in the study. Invited panellists were pulmonologists or rheumatologists with at least 5 years of experience in their speciality and in the management of patients with progressive fibrosing ILD working in European public hospitals. Panellists could answer the questionnaire through an online platform. Two rounds of voting were held between February and June 2019. The second round only included items for which no consensus was reached in the first round.

The definition of progression in fibrosing ILD used in this analysis is the one of the INBUILD trial [3, 15], albeit no results of the INBUILD trial were published at the time of the voting. Briefly, patients were considered "progressive" when they presented one of the three following criteria despite treatment for ILD: clinically significant decline of lung function $[\geq 10 \%$ relative decline in forced vital capacity (FVC) over the last 24 months]; a combination of worsening lung function $(\geq 5-<10 \%$ relative decline in FVC over the last 24 months) plus worsening respiratory symptoms or evidence of increasing fibrosis on chest imaging; or a combination of worsening respiratory symptoms and evidence of increasing fibrosis on chest imaging. This article is based on the opinion on a specific topic based on the judgment of a group of experts. For this purpose, there was no need to collect any type of patient data or information and obtaining an ethical committee approval was not needed. Also, as no patient data were collected, there was no need to obtain informed consent.

\section{Statistical Analysis}

The Delphi questionnaire included qualitative and quantitative (discrete and continuous) items. Qualitative items were evaluated with a Likert-type nine-position scale, where 1 was "completely disagree" and 9 "completely agree". The results were grouped into three categories of agreement: "disagreement" (1-3), "neither disagreement nor agreement" (4-6) and "agreement" (7-9). Median score, mean, interquartile range, and percentage of panellists in each interval of agreement were calculated. "Consensus" was defined as more than $75 \%$ of panellists voting within the "agreement" or "disagreement" intervals.

For numerical discrete variables, the percentage of panellists choosing a specific value was determined, and "consensus" was defined as $>75 \%$ panellists agreeing to a specific value.

For numerical continuous variables, mean, quartile 1 (Q1) and quartile 3 (Q3) (50\% of the central range of values obtained) were calculated, and the mean value was considered the "consensus" value.

Comparative analyses by specialty of the panellists were carried out with the chi-square test or analysis of variance (ANOVA) test for categorical and continuous variables, respectively. Data were analysed with IBM SPSS version 22.0, and $p<0.05$ was considered statistically significant.

\section{Cost Analysis}

Annual costs (per patient, by country and on average) were estimated by a direct cost-analysis study. Cost estimates were calculated as the products of the estimated number of resources 
(i.e., visits, tests, treatments-including mean doses and duration of treatment-and hospitalisations) used for diagnosis, annual number of follow-ups and adverse events management, management of exacerbations, and end-of-life care obtained from the opinion of the panellists, multiplied by their corresponding unit cost.

For yearly cost calculation, cost of diagnosis was based on the total diagnosis cost divided by the average time to diagnosis. The cost calculation of the patient's follow-up management included hospitalisation and outpatient costs. Similarly, cost of management of acute exacerbations included hospitalisation costs plus outpatient costs during exacerbation follow-up. This sum was then multiplied by the agreed event frequency. For end-of-life event cost calculation, the percentage of patients dying in the intensive care unit (ICU), hospital, home or nursing home was obtained. The cost of one admission at the ICU and at the hospital was assumed for the patients dying in this setting and the sum of costs for outpatient visits, tests and treatment resources was used for the patients dying at home or at the nursing home.

Unit costs were given by local health economists, extracted from national or regional cost databases, and published literature from the respective countries. A list of sources per country can be found in the supplementary online material (Supplementary Table S1).

When needed, unit costs were converted to 2019 value prices using the published consumer price index (CPI). Final costs were converted into euros for those countries not using this currency.

\section{Sensitivity Analysis}

A series of univariate sensitivity analyses was performed to estimate the impact of varying the values of different input parameters on the cost outcome results. Specific parameters were varied one at a time across a plausible range, while the remaining values were held at baseline values. The parameters tested were the resources used (Q1, median, and Q3 values) and the unit costs for outpatient visits, hospitalisations, drugs, laboratory tests, and imaging and other tests $( \pm 25 \%)$.

\section{RESULTS}

\section{Characteristics of Participant Panellists}

Of the 138 panellists invited to participate in the survey, 40 specialists ( 32 pulmonologists and 8 rheumatologists) completed the questionnaire for both rounds of the survey. Geographical distribution of participants was: Belgium $(n=3)$, Denmark $(n=8)$, Greece $(n=9)$, The Netherlands $(n=7), \quad$ Portugal $(n=8)$, Finland $(n=1)$, Norway $(n=2)$, and Sweden $(n=2)$.

Panellists reported that a total of 7757 patients with fibrosing ILD attended their hospitals or clinics in the last year, amongst which 2459 were IPF. Of the 5298 non-IPF fibrosing ILD patients, $31.6 \%$ presented a progressive fibrosing behaviour and $68.4 \%$ a non-/slowprogressive fibrosing ILD.

\section{Consensus on the Definition, Management, and Impact of Progressive Fibrosing ILD}

The definition of progression as used in the INBUILD trial $[3,15]$ reached large consensus among panellists (84.8\%, Fig. 1a).

The majority of panellists agreed that progression of the fibrosis can be found in a variety of ILDs other than IPF and that these might have a similar prognosis and clinical course than IPF, although agreement was not reached on similarity of survival between IPF patients and patients with other progressive fibrosing ILDs (Fig. 1a).

Panellists agreed that progressive fibrosing ILD patients can suffer from exacerbations and that these events directly impact survival, are more frequent when the disease is severe, and are the most impactful clinical events for the quality of life of progressive fibrosing ILD patients. There was no consensus on the fact that exacerbation rates are similar across all types of progressive fibrosing ILD. 
A

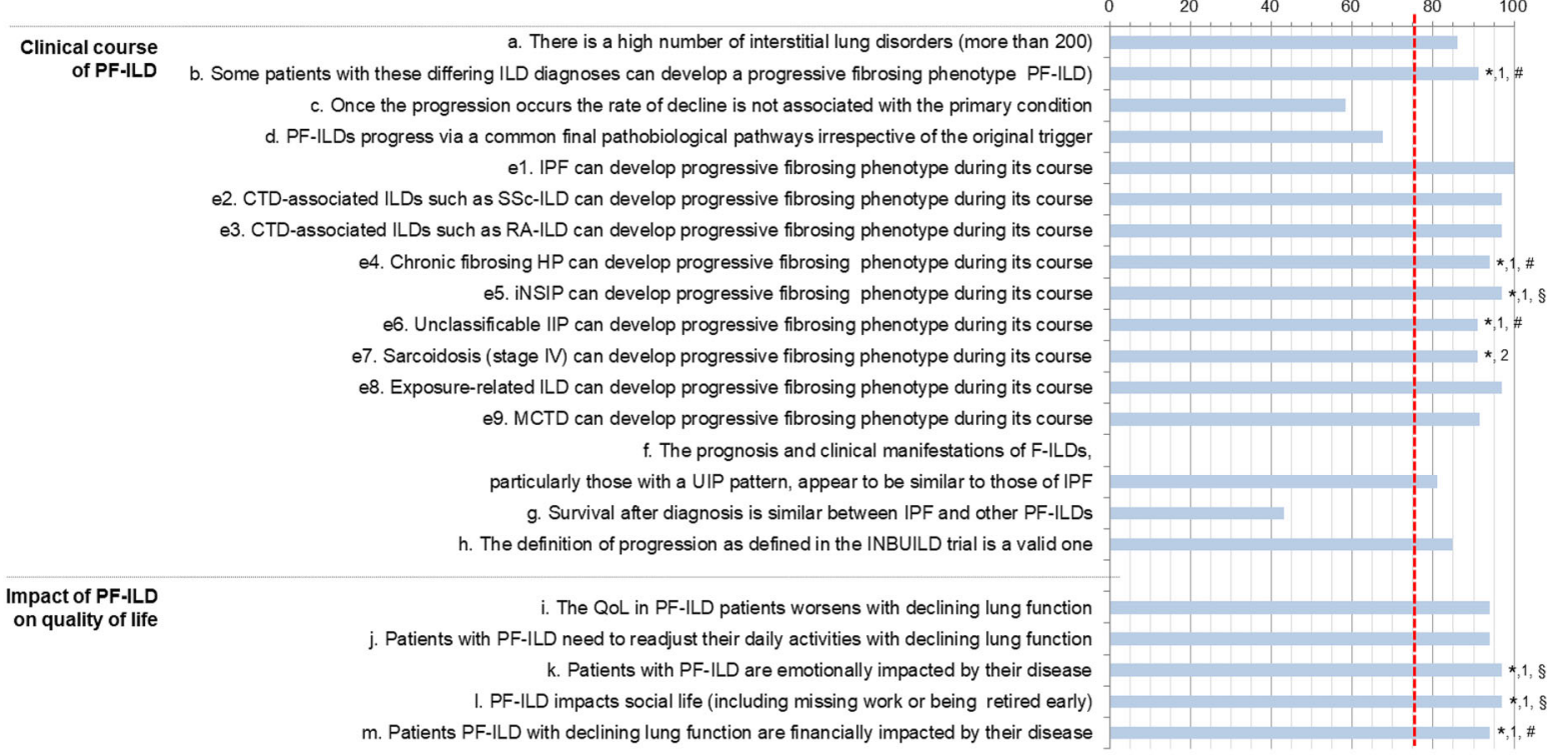

B

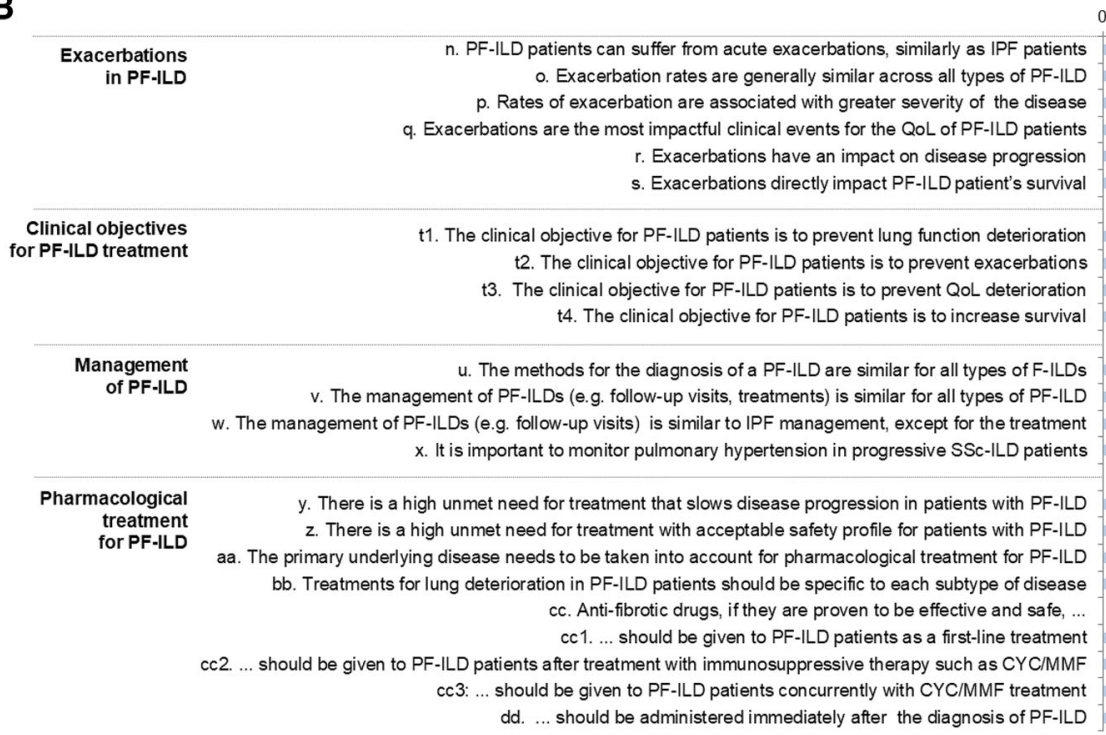

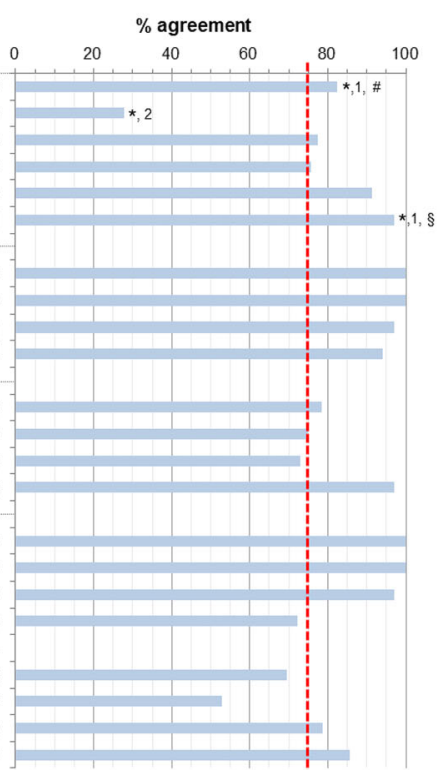

1: Comparison per specialty (pulmonologists vs. rheumatologists)

2: Comparison per country

: $p<0.05$

ists reached consensus on agreement but rheumatologists did not reach consensus on agreement

The red dotted line indicates the cut-off point for consensus $(75 \%)$

Fig. 1 a Consensus on clinical course and impact on quality of life of progressive fibrosing ILD. b Consensus on exacerbations, clinical objectives, management, and pharmacological treatment for progressive fibrosing ILD

Experts did not reach a consensus on the need for specific treatment for lung deterioration for each subtype of disease. There was a consensus to treat progressive fibrosing ILD patients with anti-fibrotic drugs at diagnosis should they be proven to be effective and safe, and concurrently with cyclophosphamide/mycophenolate mofetil, (CYC/MMF) but not as first-line treatment or after CYC/MMF (Fig. 1b). 
All respondents agreed that there is a high unmet need for a safe and effective treatment for patients with progressive fibrosing ILDs (Fig. 1b). There was a consensus on the treatment goals, which were to prevent lung deterioration, prevent exacerbations, preserve quality of life, and increase survival.

\section{Resources Used for Diagnosis}

Time from first symptoms to definite diagnosis of non-IPF fibrosing ILD was 2.3 years (mean [Q1-Q3]: 2.3 [2-3] years). For definite diagnosis, panellists indicated a mean [Q1-Q3] of 3.6 [3-4] total visits, 9.1 [7-9] laboratory tests, and 9.5 [6-12] imaging and other tests (Table 1). Among the specialists involved in making the diagnosis, pulmonologists were considered the most important (data not shown).

\section{Resources Used for Follow-Up Management and Maintenance Treatment}

Panellists agreed that pulmonologists are the main responsible physicians for the monitoring of non-IPF fibrosing ILD patients (data not shown). Overall, number of visits and tests (laboratory and imaging and other tests) used for follow-up of progressive fibrosing ILD patients was reported to be higher than for patients with non-/slow-progressive fibrosing ILD (Table 2). Similarly, panellists reported more hospitalisations per patient during the last year, and of longer duration, in patients with progressive fibrosing ILD than in patients with the non-/slow-progressive form of the disease (4.4 vs. 2.6 hospitalisations per patient and 5.9 days vs 3.9 days of duration in average, respectively, according to the panellists).

Regarding maintenance treatment, $50 \%$ of the panellists have a "watch and wait" approach for patients with non-/slow-progressive fibrosing ILD ( $21.8 \%$ of patients), while only $22.5 \%$ adopted this approach for progressive fibrosing ILD patients $(6.2 \%$ of patients). Treatment of non-/slow-progressive fibrosing ILD patients mainly consisted of systemic corticosteroids (32.1\% of patients), mycophenolate mofetil (21.4\% of patients), and azathioprine $(19.6 \%$ of patients). For progressive fibrosing ILD, a similar treatment pattern was observed but at a higher rate $(45.4 \%, 39.0 \%$, and $24.9 \%$, respectively). The use of oxygen therapy is more than four times higher in progressive fibrosing ILD compared with the non-/slow-progressive forms of the disease (29.8\% of patients vs. $7.1 \%)$. Overall, pulmonary rehabilitation sessions were indicated 1.4 times more often (Table 3). The number of patients who received lung transplantation in the last year was approximately seven times higher in progressive fibrosing ILD patients than in patients with the non-/slowprogressive form of the disease (Table 3).

Lastly, panellists estimated that $73.1 \%$ of progressive fibrosing ILD patients would benefit from antifibrotic agents if their efficacy and safety were proven and if they had a regulatory label in that indication.

Panellists reported describing adverse events (AE) using tumour necrosis factor (TNF) inhibitors, systemic corticosteroids, antifibrotics, and immunomodulatory agents in 56.7\%, 25.0\%, $22.1 \%$, and $16.2 \%$ of the patients, respectively. When patients were reported to have an $\mathrm{AE}$, the rate of hospitalisation was $19.0 \%, 100.0 \%$, $50.0 \%$, and $11.6 \%$ for immunomodulatory agents, cyclin-dependent kinase (CDK) inhibitors, TNF inhibitors, and systemic corticosteroids, respectively. For antifibrotics, antiinflammatory agents, antibiotics, and long-term oxygen, the rate of hospitalisation when an $\mathrm{AE}$ occurred was $<5 \%$ and most AEs were indicated to be managed in an outpatient setting (Supplementary Table S2).

\section{Resources Used for Exacerbations}

Panellists estimated that the number of patients who had suffered one acute exacerbation during the last year was more than two times higher in progressive fibrosing ILD patients than in patients with non-/slow-progressive fibrosing ILD (mean [Q1-Q3]: 19.7\% [10-28] vs. $7.2 \%$ [2-10], respectively). The number of patients who had suffered more than one exacerbation during the last year was more than three times higher in progressive fibrosing ILD patients than in patients with non-/slow-progressive 
Table 1 Description of resources used for diagnosis of non-IPF fibrosing ILD

\begin{tabular}{|c|c|c|}
\hline Resource & $\begin{array}{l}\text { Number of visits or tests } \\
\text { Mean }[\mathrm{Q} 1-\mathrm{Q} 3]\end{array}$ & $\begin{array}{l}\text { Number of panellists who } \\
\text { estimated a value per resource }\end{array}$ \\
\hline Number of visits per patient, total & $3.6[3-4]$ & \\
\hline Pulmonologist & $2.4[2-3]^{*}$ & 37 \\
\hline Rheumatologist & $1.2[0-2]$ & 34 \\
\hline Dermatologist & $0.2[0-0]$ & 33 \\
\hline Number of laboratory tests per patient, total & $9.1[7-9]$ & \\
\hline Complete blood count & $1.4[1-2]$ & 37 \\
\hline Sedimentation rate & $1.0[1-1]$ & 37 \\
\hline Hepatic profile & $1.1[1-1]$ & 37 \\
\hline Creatine-phosphokinase (CPK) & $1.1[1-1]$ & 37 \\
\hline Angiotensin-converting enzyme (ACE) & $0.9[1-1]$ & 37 \\
\hline Rheumatoid factor & $1.1[1-1]$ & 37 \\
\hline Antinuclear antibodies & $1.1[1-1]$ & 37 \\
\hline Urinalysis & $0.8[0-1]$ & 37 \\
\hline Other & $0.9[0-1]$ & 26 \\
\hline Number of imaging or other tests per patient, total & $11.3[8-14]^{*}$ & \\
\hline Chest radiography & $1.1[1-1]$ & 38 \\
\hline High-resolution computed tomography & $1.3[1-2]$ & 38 \\
\hline $\mathrm{CT}$ pulmonary angiogram & $0.2[0-0]$ & 38 \\
\hline Bronchoscopy & $0.9[1-1]^{* *}$ & 38 \\
\hline Sputum assessment & $0.2[0-0]^{*}$ & 37 \\
\hline Bronchoalveolar lavage & $0.9[1-1]$ & 37 \\
\hline Transbronchial biopsy & $0.5[0-1]^{*}$ & 37 \\
\hline Ventilation/perfusion scan & $0.1[0-0]$ & 37 \\
\hline Blood gases & $0.8[0-1]$ & 37 \\
\hline Spirometry & $1.5[1-2]$ & 37 \\
\hline Body plethysmography & $1.2[1-2]^{* *}$ & 37 \\
\hline Diffusing capacity of carbon monoxide & $1.5[1-2]$ & 37 \\
\hline 6 -min walk test & $1.1[1-1]$ & 37 \\
\hline Other & $0.4[0-1]$ & 20 \\
\hline
\end{tabular}

a All panellists $(N=40)$ answered all questions. When the number was $<40$, the remaining panellists filled in "I don't know"

Comparison per specialty (pulmonologists vs. rheumatologists): ${ }^{*} p<0.05 ;{ }^{* *} p<0.01 ;{ }^{* * *} p<0.001$ 
Table 2 Description of resources used during follow-up of patients with non-/slow-progressive fibrosing ILD and patients with progressive fibrosing ILD

\begin{tabular}{|c|c|c|c|}
\hline \multirow[t]{2}{*}{ Resource } & \multicolumn{2}{|c|}{$\begin{array}{l}\text { Number of visits or tests } \\
\text { Mean [Q1-Q3] }\end{array}$} & \multirow[t]{2}{*}{$\begin{array}{l}\text { Number of panellists who } \\
\text { estimated a value per resource }\end{array}$} \\
\hline & $\begin{array}{l}\text { Non-/slow- } \\
\text { progressive fibrosing } \\
\text { ILD }\end{array}$ & $\begin{array}{l}\text { Progressive } \\
\text { fibrosing ILD }\end{array}$ & \\
\hline Number of visits per patient, total & $4.7[3-5]$ & $7[5-9]$ & \\
\hline Pulmonologist & $2.7[2-4]^{* * *}$ & $3.7[3-4]^{* *}$ & 38 \\
\hline Rheumatologist & $0.9[0-1]$ & $1.1[0-2]^{*}$ & 33 \\
\hline Dermatologist & $0[0-0]$ & $0[0-0]$ & 29 \\
\hline Nurse (or other healthcare professionals) & $0.8[0-1]$ & $1.2[0-2]$ & 31 \\
\hline Pulmonologist home visit & $0.1[0-0]$ & $0.2[0-0]$ & 30 \\
\hline $\begin{array}{l}\text { Home nurse (or other homecare } \\
\text { healthcare professionals) }\end{array}$ & $0[0-0]$ & $0.2[0-0]$ & 28 \\
\hline Social workers & $0.1[0-0]$ & $0.3[0-1]$ & 28 \\
\hline Emergency room visits & $0.7[0-1]$ & $1.2[0-2]$ & $26 / 27$ \\
\hline $\begin{array}{l}\text { Number of laboratory tests per patient, } \\
\text { total }\end{array}$ & $10.6[6-12]$ & $13.6[9-19]$ & \\
\hline Complete blood count & $2.5[1-4]$ & $3.4[2-4]$ & $33 / 34$ \\
\hline Sedimentation rate & $1.5[0-3]$ & $1.9[0-3]$ & $32 / 33$ \\
\hline Hepatic profile & $2.6[1-4]$ & $3.4[2-4]$ & $32 / 33$ \\
\hline Creatine phosphokinase (CPK) & $1.2[0-2]$ & $1.4[0-2]$ & $32 / 33$ \\
\hline Angiotensin-converting enzyme (ACE) & $0.5[0-1]$ & $0.6[0-1]$ & $32 / 33$ \\
\hline Rheumatoid factor & $0.6[0-1]$ & $0.7[0-1]$ & $33 / 34$ \\
\hline Antinuclear antibodies & $0.7[0-1]$ & $0.7[0-1]$ & $32 / 33$ \\
\hline Urinalysis & $1.1[0-2]$ & $1.3[0-2]^{*}$ & $32 / 33$ \\
\hline Other & $0.3[0-0]$ & $0.8[0-0.5]$ & $19 / 20$ \\
\hline $\begin{array}{l}\text { Number of imaging or other tests per } \\
\text { patient, total }\end{array}$ & $14.2[9-22]^{*}$ & $19[15-23]^{*}$ & \\
\hline Chest x-ray & $1.3[1-2]$ & $1.6[1-2]^{*}$ & 34 \\
\hline $\begin{array}{l}\text { High-resolution computed tomography } \\
\text { (HRCT) }\end{array}$ & $0.9[1-1]$ & $1.3[1-1]$ & $33 / 34$ \\
\hline $\begin{array}{l}\text { Computed tomography pulmonary } \\
\text { angiogram }\end{array}$ & $0[0-0]$ & $0.1[0-0]$ & $31 / 32$ \\
\hline Bronchoscopy & $0.4[0-1]$ & $0.7[0-1]$ & $31 / 32$ \\
\hline Sputum assessment & $0.3[0-0]$ & $0.4[0-1]$ & $31 / 32$ \\
\hline
\end{tabular}


Table 2 continued

\begin{tabular}{|c|c|c|c|}
\hline \multirow[t]{2}{*}{ Resource } & \multicolumn{2}{|c|}{$\begin{array}{l}\text { Number of visits or testsMean [Q1- } \\
\text { Q3] }\end{array}$} & \multirow[t]{2}{*}{$\begin{array}{l}\text { Number of panellists who } \\
\text { estimated a value per resource }\end{array}$} \\
\hline & $\begin{array}{l}\text { Non-/slow- } \\
\text { progressive fibrosing } \\
\text { ILD }\end{array}$ & $\begin{array}{l}\text { Progressive } \\
\text { fibrosing ILD }\end{array}$ & \\
\hline Bronchoalveolar lavage & $0.5[0-1]$ & $0.6[0-1]$ & $31 / 32$ \\
\hline Transbronchial biopsy & $0.0[0-0]$ & $0.2[0-0]$ & $31 / 32$ \\
\hline Surgical lung biopsy & $0.4[0-0]$ & $0.3[0-0]$ & $31 / 32$ \\
\hline Cryobiopsy & $0.2[0-0]$ & $0.3[0-0]$ & $31 / 32$ \\
\hline Ventilation/perfusion scan & $0.0[0-0]$ & $0.3[0-0]$ & $30 / 31$ \\
\hline Blood gases & $0.9[0-1.1]$ & $1.5[1-2]$ & 33 \\
\hline Respiratory function tests & $2.3[1-3]^{*}$ & $2.9[2-4]^{* * *}$ & 31 \\
\hline Spirometry & $2.1[1-3]^{* *}$ & $2.7[2-4]^{* *}$ & 33 \\
\hline Bodyplethysmography & $1.4[0-2]$ & $1.5[0.5-2.5]$ & 32 \\
\hline Diffusing capacity of carbon monoxide & $2.2[1-3]^{* *}$ & $2.8[2-4]^{* * *}$ & 33 \\
\hline 6 -min walk test & $1.3[1-1]$ & $1.5[1-2]$ & 33 \\
\hline Other & $0.1[0-0]$ & $0.1[0-0]$ & 17 \\
\hline $\begin{array}{l}\text { Number of hospitalisations per patient, } \\
\text { total }\end{array}$ & $2.6[0-4]$ & $4.4[2-5]$ & \\
\hline Number of hospital admissions & $1.5[0-2]$ & $1.9[1-2]$ & 30 \\
\hline $\begin{array}{l}\text { Mean duration of a hospital admission } \\
\text { (days) }\end{array}$ & $3.9[2-5]$ & $5.9[4-7]$ & $14^{\mathrm{b}}$ \\
\hline $\begin{array}{l}\text { Number of hospital admissions at the } \\
\text { pulmonary department }\end{array}$ & $1.1[0-1.5]$ & $2.2[1-2]$ & 28 \\
\hline $\begin{array}{l}\text { Mean duration of a hospitalisation at the } \\
\text { pulmonary department (days) }\end{array}$ & $4.3[3-5]$ & $6.2[4-7]$ & $13^{\mathrm{b}}$ \\
\hline $\begin{array}{l}\text { Number of hospital admissions at the } \\
\text { intensive care unit }\end{array}$ & $0.1[0-0]$ & $0.5[0-1]$ & 27 \\
\hline $\begin{array}{l}\text { Mean duration of a hospitalisation at the } \\
\text { intensive care unit (days) }\end{array}$ & $2.5[2-3]$ & $3.4[2-5]$ & $2^{\mathrm{b}}$ \\
\hline
\end{tabular}

${ }^{a}$ Except when indicated $\left({ }^{b}\right)$, all panellists $(N=40)$ answered the question. When the number is $<40$, the remaining panellists filled in the option "I don't know". When two values are indicated, the left value indicates the number of panellists who gave a value for non-/slow-progressive F-ILD and the right value the number of panellists who gave a value for progressive fibrosing ILD

${ }^{b}$ Not all panellists answered the question. Here, the number of respondents is indicated

Comparison per specialty (pulmonologist vs. rheumatologist): ${ }^{*} p<0.05 ;{ }^{* *} p<0.01 ;{ }^{* * *} p<0.001$ 


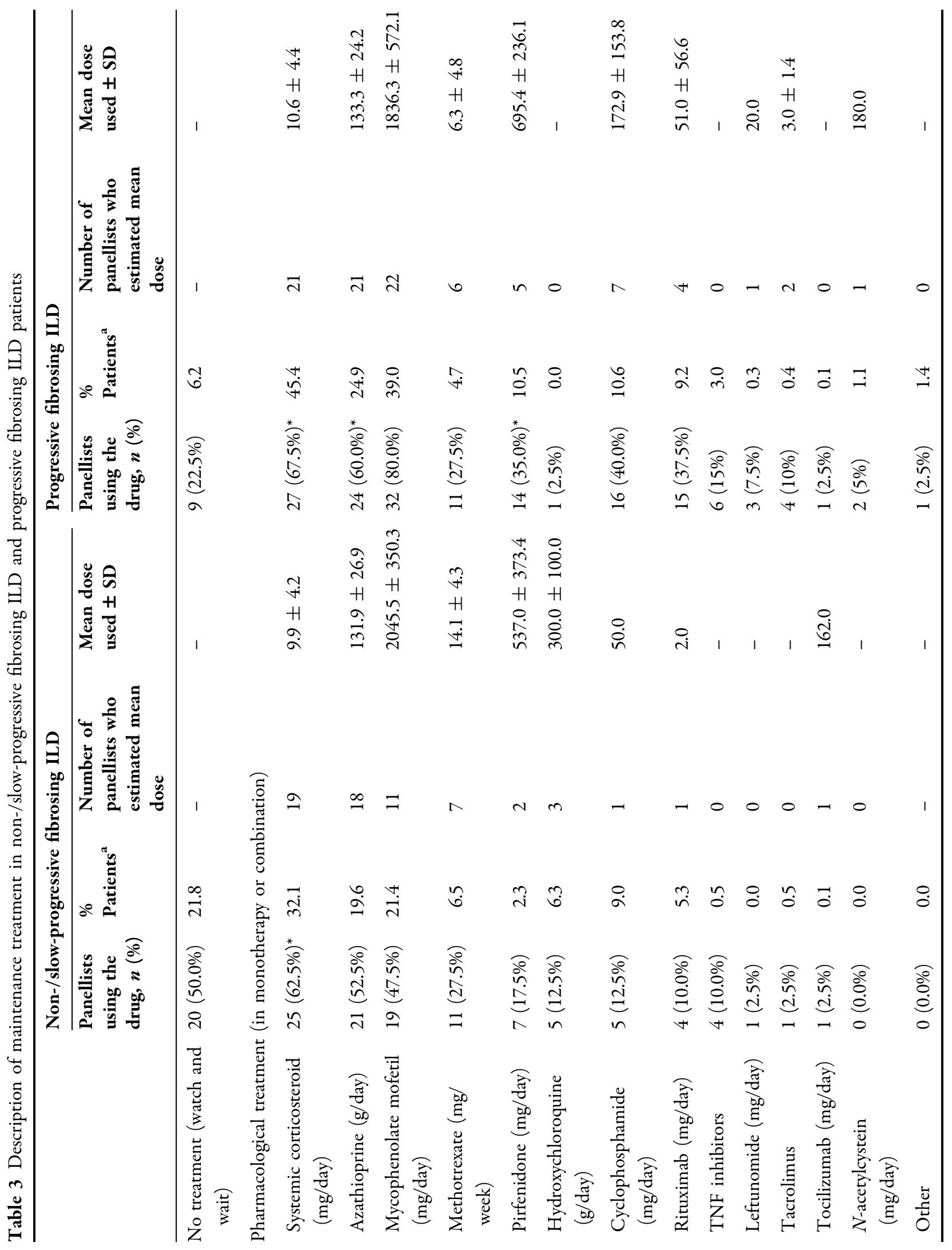




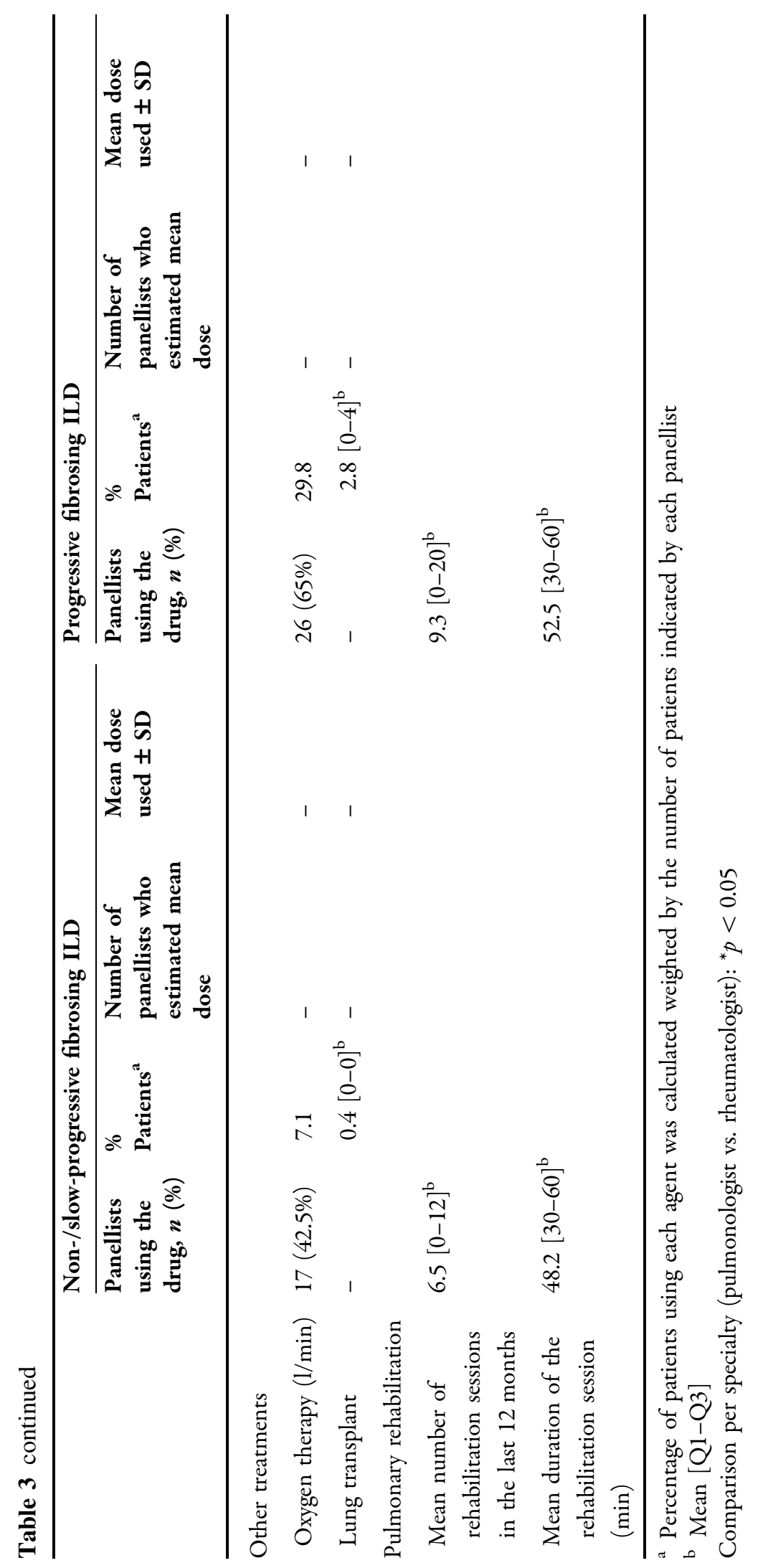


Table 4 Description of resources used for exacerbations of non-IPF fibrosing ILD

\begin{tabular}{|c|c|c|}
\hline Resource & $\begin{array}{l}\text { Number of visits } \\
\text { or tests } \\
\text { Mean }[Q 1-Q 3]\end{array}$ & $\begin{array}{l}\text { Number of panellists who estimated a } \\
\text { value per resource } \mathrm{a}^{\mathrm{a}}\end{array}$ \\
\hline Number of visits per patient, total & $6.7[4-9]$ & \\
\hline Pulmonologist & $3.2[2-4]$ & 36 \\
\hline Rheumatologist & $0.8[0-1]^{* * *}$ & 32 \\
\hline Dermatologist & $0[0-0]$ & 31 \\
\hline Nurse (or other healthcare professionals) & $1.2[0-2]$ & 30 \\
\hline Pulmonologist home visit & $0.1[0-0]$ & 33 \\
\hline $\begin{array}{l}\text { Home nurse (or other homecare healthcare } \\
\text { professionals) }\end{array}$ & $0.3[0-0]$ & $33^{\mathrm{b}}$ \\
\hline Emergency room visit & $1.8[1-2]$ & $32^{\mathrm{b}}$ \\
\hline Number of laboratory tests per patient, total & $11.5[8-12]$ & \\
\hline Complete blood count & $3.4[2-4]$ & 34 \\
\hline Sedimentation rate & $1.5[0-2]$ & 33 \\
\hline Hepatic profile & $2.8[2-4]$ & 33 \\
\hline Creatine phosphokinase (CPK) & $1.6[0-2]^{*}$ & 33 \\
\hline Angiotensin-converting enzyme (ACE) & $0.5[0-0]$ & 33 \\
\hline Rheumatoid factor & $0.3[0-1]$ & 33 \\
\hline Antinuclear antibodies & $0.4[0-1]$ & 33 \\
\hline Urinalysis & $1[0-1]$ & 33 \\
\hline Other & $0.3[0-0]$ & 23 \\
\hline Number of imaging or other tests per patient, total & $19.8[12-24]$ & \\
\hline Chest $\mathrm{x}$-ray & $2.1[1-3]$ & 35 \\
\hline High-resolution computed tomography (HRCT) & $1.4[1-1.3]^{*}$ & 35 \\
\hline Computed tomography pulmonary angiogram & $1.0[0-1]$ & 34 \\
\hline Bronchoscopy & $0.9[0-1]$ & 33 \\
\hline Sputum assessment & $1[0-1.5]$ & 33 \\
\hline Bronchoalveolar lavage & $0.9[0-1]$ & 34 \\
\hline Transbronchial biopsy & $0.1[0-0]^{* * *}$ & 33 \\
\hline Surgical lung biopsy & $0.0[0-0]$ & 33 \\
\hline Ventilation/perfusion scan & $0.2[0-0]$ & 33 \\
\hline Blood gases & $3.1[1-4]$ & 34 \\
\hline Respiratory function tests & $2.0[0-3]$ & 34 \\
\hline
\end{tabular}


Table 4 continued

\begin{tabular}{|c|c|c|}
\hline Resource & $\begin{array}{l}\text { Number of visits } \\
\text { or testsMean } \\
{[Q 1-Q 3]}\end{array}$ & $\begin{array}{l}\text { Number of panellists who estimated a } \\
\text { value per resource }{ }^{\mathrm{a}}\end{array}$ \\
\hline Spirometry & $2.0[0-3]$ & 34 \\
\hline Body plethysmography & $1.2[0-1]$ & 33 \\
\hline Diffusing capacity of carbon monoxide & $1.9[0-3]$ & 34 \\
\hline 6-min walk test & $0.6[0-1]$ & 34 \\
\hline Oxygen therapy & $2.1[1-2]$ & 32 \\
\hline Other & $0.1[0-0]$ & 17 \\
\hline Number of hospitalisations per patient, total & $6[2-6]$ & \\
\hline Number of hospital admissions & $2.4[1-3]$ & 31 \\
\hline Mean duration of a hospital admission (days) & $8.2[6-10$ & $29^{\mathrm{b}}$ \\
\hline $\begin{array}{l}\text { Number of hospital admissions at the pulmonary } \\
\text { department }\end{array}$ & $2.9[1-3]$ & 29 \\
\hline $\begin{array}{l}\text { Mean duration of a hospitalisation at the pulmonary } \\
\text { department (days) }\end{array}$ & $7.2[4-10]$ & $27^{\mathrm{b}}$ \\
\hline $\begin{array}{l}\text { Number of hospital admissions at the intensive care } \\
\text { unit }\end{array}$ & $0.9[0-1]$ & 29 \\
\hline $\begin{array}{l}\text { Mean duration of a hospitalisation at the intensive } \\
\text { care unit (days) }\end{array}$ & $4.8[3-7]$ & $12^{\mathrm{b}}$ \\
\hline
\end{tabular}

${ }^{a}$ Except when indicated $\left({ }^{b}\right)$, all panellists $(N=40)$ answered the question. When the number was $<40$, the remaining panellists filled in the option "I don't know"

${ }^{\mathrm{b}}$ Not all panellists answered the question. Here, the number of respondents is indicated

Comparison per specialty (pulmonologist vs. rheumatologist): ${ }^{*} p<0.05 ;{ }^{* *} p<0.01 ;{ }^{* * *} p<0.001$

fibrosing ILD $(6.1 \% \quad[0-10]$ vs. $1.7 \%$ [0-2], respectively).

On average, exacerbations and their followup accounted for a mean [Q1-Q3] of 6.7 [4-9] visits to healthcare professionals, 11.5 [8-12] laboratory tests, 19.8 [12-24] imaging and other tests, and 6 [2-6] hospital admissions (Table 4). The main agents used to treat exacerbations were antibiotics, prednisone, and methylprednisolone (in 82\% [75-100], 45.9\% [0-100], and $44.5 \%$ [0-80] of the patients with acute exacerbation, respectively).

\section{End-of-Life Care}

Lastly, panellists estimated that palliative care is administered for 6.1 months [3-6] in patients with progressive fibrosing ILD, mostly in hospitals $(39.8 \%)$ or at home $(35.6 \%)$.

\section{Burden of Disease: Cost Analysis}

Overall, the total annual costs per progressive fibrosing ILD patient were 1.8 higher than the costs per patient with the non-/slow-progressive form of the disease, with an average of $€ 34,530.08$ for progressive fibrosing ILD vs. $€ 18,745.57$ for non-/slow-progressive fibrosing 


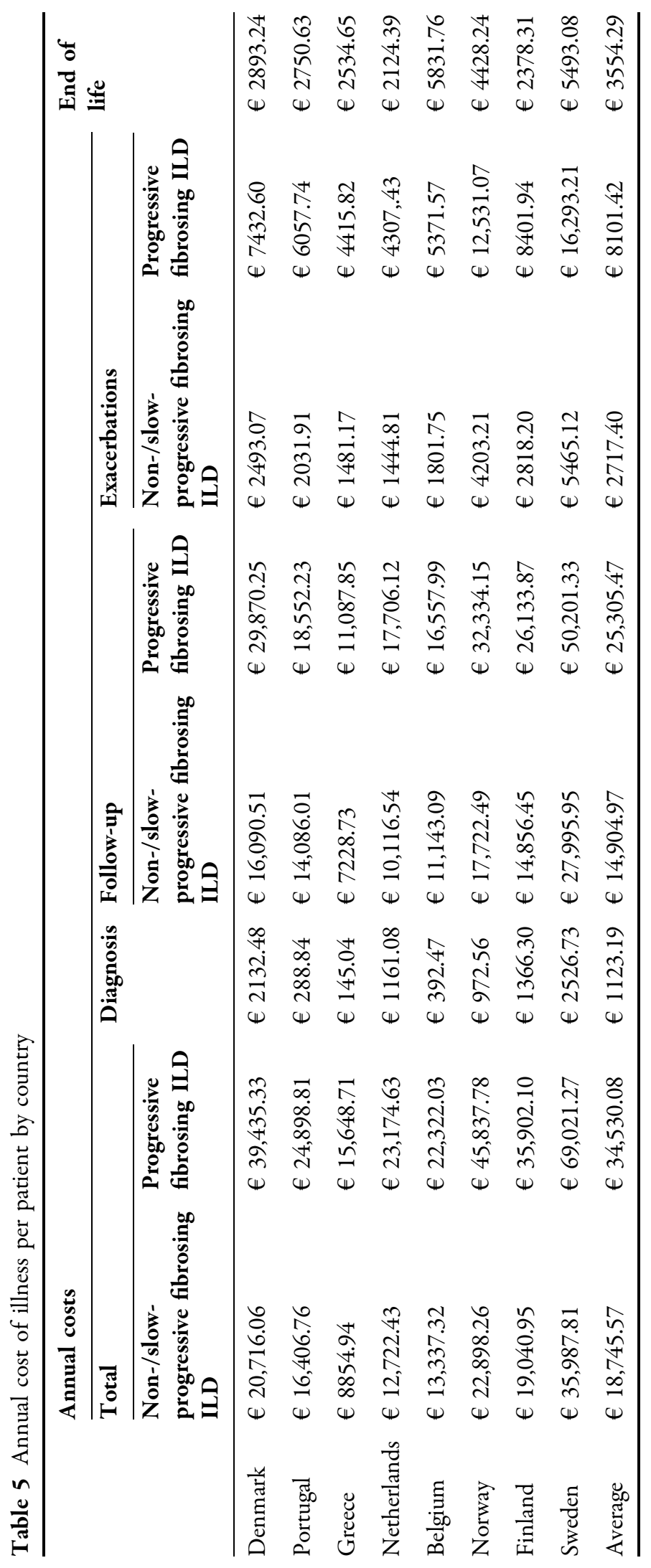



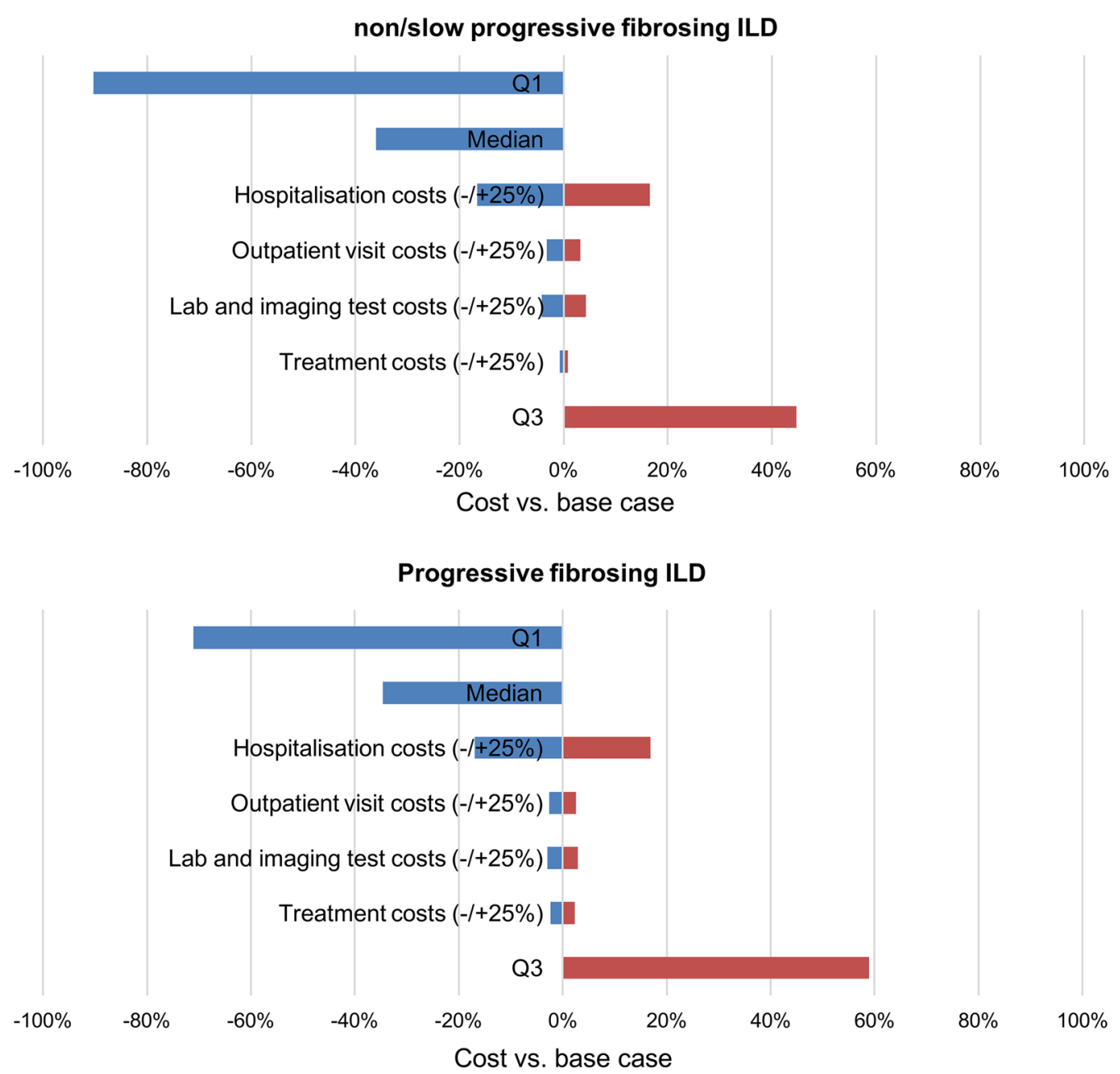

Fig. 2 Univariate deterministic sensitivity analysis

ILD (Table 5). Among follow-up costs, costs per visits, hospitalisations, and tests were the main cost drivers (data not shown).

\section{Sensitivity Analyses}

Q1 and Q3 values for healthcare resource use had the most impact on the cost of the disease. The cost of both forms of fibrosing ILD was more sensitive to lower use of resources (Q1). The most important cost driver was hospitalisation, for which a variation of $25 \%$ of costs represented an overall variation of $17 \%$ of total yearly costs (Fig. 2).

\section{Burden of Disease: Impact on Quality of Life}

Panellists agreed that progressive fibrosing ILD negatively impacts both patients' and unpaid carers' quality of life. Up to $45.6 \%$ of patients suffer fatigue according to the panellists. The most common comorbidities reported by the panellists included pulmonary infection (29.3\%), depression (27.2\%), osteoporosis (20.3\%), and pulmonary hypertension (19.8\%) (Supplementary Table S3). Experts agreed that quality of life of progressive fibrosing ILD patients is related to lung function, and $>93 \%$ of respondents agreed that progressive fibrosing ILD affects patients' quality of life on quality of life subdomains, i.e. emotional, social, and 
financial domains (Fig. 1a). Similarly, 85 to $90 \%$ of panellists agreed that progressive fibrosing ILD impacts unpaid carers' quality of life in terms of sleep and health, daily activities, emotional well-being, social life, and finances (data not shown).

Panellists estimated that $71.2 \%$ of their progressive fibrosing ILD patients are retired and that $26.7 \%$ had retired early because of illness (data not shown). Overall, respondents estimated that $19.6 \%$ and $48.1 \%$ of non-/slowprogressive vs. progressive fibrosing ILD patients, respectively, had total permanent disability and $8.8 \%$ and $22.8 \%$ lost their job because of disability, respectively (Supplementary Table S4). Finally, it was reported that $20.3 \%$ of patients required support from a paid carer, for an average duration of $8 \mathrm{~h}$ per week, while $60.5 \%$ of patients needed support from an unpaid carer such as a partner, family member, or neighbour, for $29.8 \mathrm{~h}$ per week (data not shown).

\section{DISCUSSION}

Non-IPF fibrosing ILD affects a significant number of patients; however, little is known about its management and burden as well as the effect of disease progression on patients' quality of life, healthcare resource use, and costs. The results of this Delphi survey show a significant effect of disease progression in fibrosing ILD patients' prognosis and quality of life, and on the economic burden of the disease.

Panellists agreed that progression of fibrosis can occur in $13-40 \%$ of patients with different fibrotic ILDs, including those with connective tissue disease-associated ILD (CTD-ILD)—such as systemic sclerosis-associated ILD (SSc-ILD); rheumatoid arthritis-associated ILD (RA-ILD) and mixed CTD-ILD; chronic fibrosing hypersensitivity pneumonitis; idiopathic non-specific interstitial pneumonia; unclassifiable idiopathic interstitial pneumonia; sarcoidosis and exposure-related ILD. In our study, physicians reported that approximately a third of their non-IPF fibrosing ILD patients were progressive.

Progression of fibrosis in ILD has been associated with poor prognosis [1, 5]. A recent physicians' survey estimated that the mortality of progressive fibrosing ILD patients is similar to that of IPF patients, with a median of $4-5$ years of survival from diagnosis [5]. Interestingly, in our study panellists did not reach a consensus on it, but they agreed that progressive fibrosing ILD has a similar prognosis and clinical manifestations to IPF, especially in patients with the UIP pattern. This could be because there is still limited evidence on the survival of PF-ILD patients especially when other organs are involved, while a rapid decline of lung functions and exacerbations occur in both PF-ILD and IPF patients.

Acute exacerbations of IPF are clinically meaningful events associated with poor prognosis and increased mortality [16]. Similarly, available data suggest that exacerbations of progressive fibrosing ILD associate with an increase of hospitalisations and decrease of survival [17]. Panellists did not reach consensus regarding the similarity of exacerbation rates across different types of progressive fibrosing ILD, but they reported more exacerbations in progressive fibrosing ILD patients than in patients with non-/slow-progressive fibrosing ILD. The percentage of progressive fibrosing ILD patients who suffered at least one exacerbation in the last year more than doubled that of those with non-slow progressive fibrosing ILD. In agreement with the literature [17], panellists agreed that exacerbations of progressive fibrosing ILD directly impact patient's quality of life, disease progression, and survival. Moreover, physicians reported that progression had a significant impact on quality of life not only for progressive fibrosing ILD patients but also for patients' unpaid carers. Progression affected daily functioning and had a social and emotional impact on both groups.

In this study, a variety of treatments prescribed to progressive fibrosing ILD patients was observed. This heterogeneity might be explained by the lack of an approved treatment for the disease. In addition, this is a cluster of various diseases. Systemic corticosteroids were prescribed for $62.5 \%$ and $67.5 \%$ of patients with non-/slow-progressive fibrosing ILD and progressive fibrosing ILD, in monotherapy or in combination, even though there is little 
evidence of their efficiency for these diseases. For progressive fibrosing ILD, mycophenolate mofetil, which showed positive results in a phase-II trial in SSc-ILD [18], was the most commonly prescribed drug.

Panellists agreed that there is an unmet need for a safe and effective treatment for progressive fibrosing ILD patients. Recently, and after the second wave of voting was analysed, results from two clinical trials testing the effect of antifibrotic agents on disease progression in non-IPF fibrosing ILD patients have been published $[15,19]$. Although it was impossible to apply the prespecified statistical model for analysis of the primary end point, key secondary end point analysis of a double-blind, placebo-controlled, phase 2 trial suggest that pirfenidone may reduce the decline in FVC in patients with unclassifiable progressive fibrosing ILD [19]. Moreover, in the INBUILD trial, a double-blind, placebo-controlled, phase 3 trial, nintedanib showed efficacy in reducing the decline in FVC $(-80.8 \mathrm{ml} /$ year $)$ compared with placebo $(-187.8 \mathrm{ml} /$ year $) \quad(p<0.001)$, with consistent efficacy across patients with and without a usual interstitial pneumonia-like pattern [15]. In our study, panellists estimated that $73.1 \%$ of progressive fibrosing ILD patients and $32.2 \%$ of patients with non-/slow-fibrosing ILD would benefit from antifibrotic agents. The panellists answered the questionnaire before these data were available; hence, results might differ once new molecules are registered and available to patients.

Management of progressive fibrosing ILD is complex and requires input from multiple specialists and specialist visits, tests, and treatments. Progressive fibrosing ILD patients had more follow-up visits and needed more treatment than patients without progression, including pharmacological treatment, and oxygen therapy (percentage of patients receiving treatment was approximately four times higher for progressive fibrosing ILD than for non-/slow-progressive fibrosing ILD), pulmonary rehabilitation (approximately 1.4 times higher), and lung transplantation (approximately 7 times higher). On average, total annual costs per progressive fibrosing ILD patient were 1.8 times higher than annual costs per patient with the non-/slow-progressive form of the disease. Overall, progression in fibrosing ILD significantly increased the costs of followup management and management of exacerbations.

This study has limitations. A Delphi questionnaire was used to estimate management and healthcare resource use of progressive fibrosing ILD patients, and thus the estimated values depend on panellists' clinical experience, specialty, and practice, which may not be fully representative of general clinical practice in all the participating countries, especially in the Nordic countries where a limited number of panellists were involved. Pulmonologists were considered as the most important figure for the diagnosis and management of patients. As some types of ILD such as SSc-ILD or RA-ILD can be managed by rheumatologists, their involvement was considered necessary and their participation accounted for less than a quarter of the pool of panellist. Management patterns may differ according to the specialty and combining results from both pulmonologists and rheumatologists may generate bias in the analysis. Second, the healthcare resource use data from different countries were averaged, and therefore the differences in progressive fibrosing ILD management between countries could not be detected. Moreover, it should be noted that cost comparison between countries should be done with caution. The costs of progressive fibrosing ILD were calculated per country by applying local costs, following recommendations of local health economists. Official prices differ between countries; for instance, in The Netherlands and Belgium official prices for medicines are pharmacy purchasing prices and include valueadded tax (VAT) while in Denmark they do not include VAT.

The study results are based on the opinion of 40 panellists specialised in pulmonology and rheumatology. As data of healthcare resource use in primary and secondary care are not available in all participating countries, the Delphi method approach has allowed us to better understand the management and burden of disease of progressive fibrosing ILD. 


\section{CONCLUSIONS}

Based on a European survey, this study shows that progression of fibrosing ILD is associated with increased exacerbations, worse patient quality of life, and increased healthcare resource use and costs. Agents that prevent disease progression would benefit patients and reduce the burden of disease.

\section{ACKNOWLEDGEMENTS}

We thank the panellists for their participation in the Delphi study and the Adelphi team (Maite Artés, Isabel Soto, and Alba Llopis) for the management of the project and medical writing contributions. We also thank the local health economists who provided the information on unit prices for cost analysis (LINK Medical Research AS, Norway; INCENTIVE, Denmark; ASC Academics, The Netherlands; AIDFM, Portugal; ECONCARE Health Research and Consulting, Greece)

Funding. The BUILDup project and the journal's Rapid Service and Open Access Fees were supported by Boehringer Ingelheim.

Medical Writing Assistance. Medical writing assistance was provided by Alba Llopis Gómez and Alba Gómez Hierro and was funded by Boehringer Ingelheim.

Authorship. All named authors meet the International Committee of Medical Journal Editors (ICMJE) criteria for authorship for this article, take responsibility for the integrity of the work as a whole, and have given their approval for this version to be published.

Authorship Contributions. All authors reviewed the manuscript for medical and scientific accuracy as well as for intellectual property considerations. All authors have actively contributed to the development of the work and to the drafting of the manuscript. MA designed the questionnaire, was responsible for contacting panellists, and analysed the results.
WW, SP, EM, JRD, JM, CRC, MK, GA, and SS reviewed the questionnaire and proposed changes. DC and SS performed the cost and sensitivity analyses. At every milestone of the study, all authors reviewed and validated the documents (questionnaire, results report and manuscript) to ensure independence and lack of bias.

Disclosures. Wim A. Wuyts, Spyridon Papiris, and Effrosyni Manali are members of the advisory board and received funding for congress participation from BI and Roche. Jesper Rømhild Davidsen has received consulting fees for participating in Danish advisory meetings for BI. Jelle Miedema has received consulting fees from BI CRC. Maritta Kilpeläinen and Antonio Morais have nothing to disclose. Maite Artés is an employee of Adelphi Spain. David Cendoya, Guus Asijee, and Stéphane Soulard are employees of Boehringer Ingelheim.

Compliance with Ethics Guidelines. This article is based on the opinion on a specific topic based on the judgment of a group of experts. For this purpose, there is no need to collect any type of patient data or information and obtaining an ethical committee approval is not needed. Also, as no patient data were collected, there was no need to obtain informed consent.

Data Availability. All data relevant to the study are included in the article or uploaded as supplementary information.

Open Access. This article is licensed under a Creative Commons Attribution-NonCommercial 4.0 International License, which permits any non-commercial use, sharing, adaptation, distribution and reproduction in any medium or format, as long as you give appropriate credit to the original author(s) and the source, provide a link to the Creative Commons licence, and indicate if changes were made. The images or other third party material in this article are included in the article's Creative Commons licence, unless indicated otherwise in a credit line to the material. If material is not included in the article's Creative 
Commons licence and your intended use is not permitted by statutory regulation or exceeds the permitted use, you will need to obtain permission directly from the copyright holder. To view a copy of this licence, visit http:// creativecommons.org/licenses/by-nc/4.0/.

\section{REFERENCES}

1. Cottin V, Hirani NA, Hotchkin DL, Nambiar AM, Ogura T, Otaola $M$, et al. Presentation, diagnosis and clinical course of the spectrum of progressivefibrosing interstitial lung diseases. Eur Respir Rev. 2018;27(150):180076.

2. Raghu G, Collard HR, Egan JJ, Martinez FJ, Behr J, Brown KK, et al. An official ATS/ERS/JRS/ALAT statement: idiopathic pulmonary fibrosis: evidencebased guidelines for diagnosis and management. Am J Respir Crit Care Med. 2011;183(6):788-824.

3. Flaherty KR, Brown KK, Wells AU, Clerisme-Beaty E, Collard HR, Cottin V, et al. Design of the PF-ILD trial: a double-blind, randomised, placebo-controlled phase III trial of nintedanib in patients with progressive fibrosing interstitial lung disease. BMJ Open Respir Res. 2017;4(1):1-7.

4. Wells AU, Brown KK, Flaherty KR, Kolb M, Thannickal VJ. What's in a name? That which we call IPF, by any other name would act the same. Eur Respir J. 2018;51(5):1-12.

5. Wijsenbeek $M$, Kreuter $M$, Olson A, Fischer A, Bendstrup E, Wells CD, et al. Progressive fibrosing interstitial lung diseases: current practice in diagnosis and management. Curr Med Res Opin. 2019, $1-10$.

6. Olson AL, Gifford AH, Inase N, Fernández Pérez ER, Suda T. The epidemiology of idiopathic pulmonary fibrosis and interstitial lung diseases at risk of a progressive-fibrosing phenotype. Eur Respir Rev. 2018;27(150):180077.

7. Olson A, Hartmann N, Schlenker-Herceg R, Wallace L. Prevalence of progressive fibrosing interstitial lung disease. ERS Int Congr. 2018;PA3030.

8. Duchemann B, Annesi-Maesano I, Jacobe de Naurois C, Sanyal S, Brillet P-Y, Brauner $M$, et al. Prevalence and incidence of interstitial lung diseases in a multi-ethnic county of Greater Paris. Eur Respir J. 2017;50(2):1602419.

9. Karakatsani A, Papakosta D, Rapti A, Antoniou KM, Dimadi M, Markopoulou A, et al. Epidemiology of interstitial lung diseases in Greece. Respir Med. 2009;103(8):1122-9.

10. Thomeer MJ, Costabe U, Rizzato G, Poletti V, Demedts M. Comparison of registries of interstitial lung diseases in three European countries. Eur Respir J Suppl. 2001;32:114s-8s.

11. Kreuter M, Swigris J, Pittrow D, Geier S, Klotsche J, Prasse A, et al. Health related quality of life in patients with idiopathic pulmonary fibrosis in clinical practice: insights-IPF registry. Respir Res. 2017;18(1):139.

12. Swigris JJ, Brown KK, Abdulqawi R, Buch K, Dilling DF, Koschel D, et al. Patients' perceptions and patient-reported outcomes in progressive-fibrosing interstitial lung diseases. Eur Respir Rev. 2018. https://doi.org/10.1183/16000617.0075-2018.

13. Diamantopoulos A, Wright E, Vlahopoulou K, Cornic L, Schoof N, Maher TM. The burden of illness of idiopathic pulmonary fibrosis: a comprehensive evidence review. Pharmacoeconomics. 2018;36(7):779-807.

14. Holtze C, Flaherty K, Kreuter M, Luppi F, Moua T, Vancheri $\mathrm{C}$, et al. Healthcare utilisation and costs in the diagnosis and treatment of progressive-fibrosing interstitial lung diseases. Eur Respir Rev. 2018;27(150):180076.

15. Flaherty KR, Wells AU, Cottin V, Devaraj A, Walsh SLF, Inoue $\mathrm{Y}$, et al. Nintedanib in progressive fibrosing interstitial lung diseases. N Engl J Med. 2019;381(18):1718-27.

16. Song JW, Hong SB, Lim CM, Koh Y, Kim DS. Acute exacerbation of idiopathic pulmonary fibrosis: incidence, risk factors and outcome. Eur Respir J. 2011;37(2):356-63.

17. Kolb M, Bondue B, Pesci A, Miyazaki Y, Song JW, Bhatt NY, et al. Acute exacerbations of progressivefibrosing interstitial lung diseases. Eur Respir Rev. 2018;27(150):1-8.

18. Tashkin DP, Roth MD, Clements PJ, Furst DE, Khanna D, Kleerup EC, et al. Mycophenolate mofetil versus oral cyclophosphamide in scleroderma-related interstitial lung disease (SLS II): a randomised controlled, double-blind, parallel group trial. Lancet Respir Med. 2016;4(9):708-19.

19. Maher TM, Corte TJ, Fischer A, Kreuter M, Lederer DJ, Molina-Molina M, et al. Pirfenidone in patients with unclassifiable progressive fibrosing interstitial lung disease: a double-blind, randomised, placebocontrolled, phase 2 trial. Lancet Respir Med. 2019. https://doi.org/10.1016/S2213-2600(19)30341-8. 